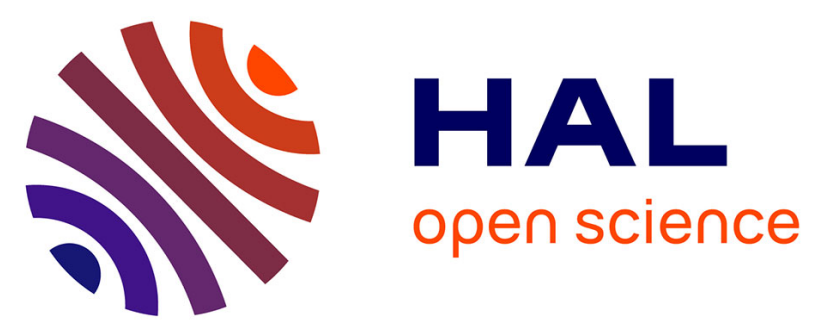

\title{
Suicidal Behavior of Young Immigrant Women in The Netherlands. Can we use Durkheim's concept of 'fatalistic suicide' to explain their high incidence of attempted suicide?
}

Diana Debora van Bergen, Sawitri Saharso, Johannes H. Smit, Anton van Balkom

\section{To cite this version:}

Diana Debora van Bergen, Sawitri Saharso, Johannes H. Smit, Anton van Balkom. Suicidal Behavior of Young Immigrant Women in The Netherlands. Can we use Durkheim's concept of 'fatalistic suicide' to explain their high incidence of attempted suicide?. Ethnic and Racial Studies, 2009, 32 (2), pp.302322. 10.1080/01419870802315043 . hal-00513311

\section{HAL Id: hal-00513311 \\ https://hal.science/hal-00513311}

Submitted on 1 Sep 2010

HAL is a multi-disciplinary open access archive for the deposit and dissemination of scientific research documents, whether they are published or not. The documents may come from teaching and research institutions in France or abroad, or from public or private research centers.
L'archive ouverte pluridisciplinaire HAL, est destinée au dépôt et à la diffusion de documents scientifiques de niveau recherche, publiés ou non, émanant des établissements d'enseignement et de recherche français ou étrangers, des laboratoires publics ou privés. 


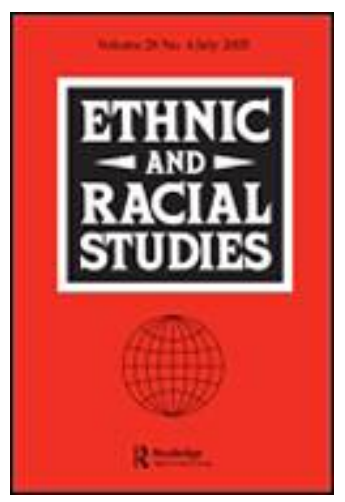

Suicidal Behavior of Young Immigrant Women in The Netherlands.

Can we use Durkheim's concept of 'fatalistic suicide' to explain their high incidence of attempted suicide?

\begin{tabular}{|r|l|}
\hline Journal: & Ethnic and Racial Studies \\
\hline Manuscript ID: & RERS-2007-0242.R2 \\
\hline Manuscript Type: & Original Manuscript \\
\hline Keywords: & $\begin{array}{l}\text { Gender and Immigration, Mental Illness, Children of immigrants, } \\
\text { The Netherlands, behavioural autonomy, cultural factors }\end{array}$ \\
\hline \multicolumn{2}{|c}{} \\
\hline
\end{tabular}

\section{S ScholarONE" \\ Manuscript Central}




\begin{abstract}
Young immigrant women of South Asian, Turkish and Moroccan origin in The Netherlands demonstrate disproportionate rates of non-fatal suicidal behavior. Suicidal behavior is usually explained from a psychological or medical tradition. However, we would like to emphasize sociological correlates, by examining the relevance of Durkheim's fatalistic suicide, characterized by overregulation. We conducted a retrospective analysis of 115 case files of young women who demonstrated suicidal behavior to illuminate their living conditions. The analysis included a comparison of class factors as well as psychiatric and psychological risk factors. In at least half of the cases South Asian, Turkish and Moroccan women experienced specific stressful life events related to their family honor. Women's lives were often characterized by a lack of self-autonomy. It is concluded that the archetype of fatalistic suicide should be re-evaluated when interpreting the suicidal behavior of young immigrant women in The Netherlands and incorporated in strategies of prevention.
\end{abstract}

Keywords: Gender and Immigration, Mental Illness, Children of immigrants, The Netherlands, behavioural autonomy, cultural factors

\title{
Introduction
}

Two epidemiological studies carried out in the city of The Hague showed that young women from certain ethnic minority groups more often demonstrate non-fatal suicidal behavior than Dutch young women (Schudel et al, 1998; Burger et al, 2005). This suggests that a substantial group of young immigrant women in The Netherlands suffer from severe difficulties and distress in life. In the late nineties, the rates of suicidal behavior of South Asian, Turkish and Moroccan women in the age range of 15-24 years old appeared to be two to four times higher than that of majority Dutch young women. ${ }^{1}$ By 2005 , the rates for South Asian and Turkish young females continued to be disproportionate, while those of Moroccan young women were still increased compared to Dutch young women- yet not statistically 
significant. The reports on the alarming rates of suicidal behavior of young immigrant women occasioned the research into the background of this phenomenon. ${ }^{2}$

Suicidal behavior is defined by the World Health Organization (WHO) as: 'a non habitual act with a non-fatal outcome that the individual, expecting to, or taking the risk todie or inflict bodily harm, initiated and carried out with the purpose of bringing about wanted changes' (De Leo et al, 2005). It concerns behavior including self-poisoning by taking an overdose of pills or cutting the wrist(s). The desired change includes, but is often not limited to, the intent to die. In addition, desired changes may include a wish to escape from an unbearable situation or thoughts, the search for peace of mind or the wish to communicate to others how much they are in mental pain (Hjelmelandt et al, 2002).

Research in suicidology usually explains suicidal behavior almost exclusively by psychiatric and psychological risk factors e.g. mental illness and dysfunction in personality. However, studies have pointed at the possible relevance of sociological theory of Durkheim's fatalistic suicide of young women worldwide originating in overregulated lives and their discontent with their social roles (see for instance, Iga (1981) on suicidal behavior of Japanese women or Davies and Neal (2000) on the suicide of women in rural China). Two Dutch studies based on interviews with female South Asian students aged between 16 and 24 indicated that they are often faced with high levels of control exercised by their parents (Salverda 2004, Krikke et al 1999). This led us to analyse the relevance of Emile Durkheim's concept of fatalistic suicide for understanding the suicidal behavior in young South Asian as well as Turkish and Moroccan women in The Netherlands (van Bergen et al, 2006).

Durkheim's work was based on an investigation of records of suicide in the late nineteenth century, when registration of non-fatal cases of suicidal behavior did not yet exist. Across all ethnic groups in The Netherlands, men commit suicide twice as often as women, while more women than men attempt suicide. ${ }^{3}$ This disparity is known as the gender paradox in suicidology. This pattern of male to female ratio (2:1 up to 3:1) can be observed world- wide (with exception of rural China, where more women than men die by suicide) 
(Beautrais, 2003; Canetto \& Lester, 1995). Durkheim's focus on lethal cases, as well as the male to female ratio in suicide statistics precipitates the question whether it is justified to use Durkheim's concepts for examining the non-fatal suicidal behavior of young women. However, recent research indicates that those young individuals who die by suicide and those who attempt are not a distinct population but rather a similar group. Beautrais (2003) established by a case control study that those youngsters (15-24 years old) who die by suicide and those who attempt suicide share common sociological characteristics, psychiatric diagnostic and psychiatric history features. These features concern an exposure to recent stressful life events, lack of formal educational qualifications, a mood disorder and a history of psychiatric care. Beautrais argues that the fact that men more often die by suicide than women could hence be attributed to their choice of more lethal methods. This proposition is supported by the fact that female youth suicides in New Zealand more than doubled from 1977 to 1996 , notably due to the increased use of hanging and vehicle exhaust gas by women. These findings argue against a rigid separation of lethal versus non-lethal suicidal behavior. Therefore, we believe it is justified to use Durkheim's theory for our focus on the non-fatal suicidal behavior of immigrant women.

In this paper, our research procedures and research subjects will be described first. Subsequently we investigate the contribution of psychiatric and psychological risk factors and incidences of abuse and then the results will be compared. Durkheim's archetype of fatalistic suicide will be described next. Since the registration of suicidal behavior indicate a relation between suicidal behavior, gender and ethnicity we also verify how regulation can be understood in the light of these markers. Subsequently, we demonstrate the cultural context of South Asian, Turkish and Moroccan young women who demonstrated suicidal behavior by providing a number of case file summaries. We conclude and discuss the relevance of Durkheim's theory for explaining and preventing the suicidal behavior of young minority women.

\section{Methodology and Description of the Sample}


Durkheim was criticized for the fact that he solely categorized on the basis of external and observable characteristics by using aggregated level data (for instance on divorce rate, income level or urbanization rate). By neglecting to study the individual dispositions, suicides are treated as to occur in a social void, without reference to values and beliefs that constitute the cultural milieus of individuals (Hamlin \& Brym, 2006). By contrast, in our study we focused on collecting data that could illuminate the specific social environment and living conditions of young women. We thus chose to investigate medical case files consisting of accounts of mental health care workers on the lives of young women.

We selected case files ( $\mathrm{N}=115$, mean age 23.5, $\mathrm{SD}=6.6$ ) of females between 12 and 41 years old of South Asian $(\mathrm{N}=24 \text {, mean age } 25.3, \mathrm{SD}=5.9)^{4}$, Turkish $(\mathrm{N}=32$, mean age 23.7, $\mathrm{SD}=6.7)$, Moroccan $(\mathrm{N}=30$, mean age 23.7, $\mathrm{SD}=6.4)$ and Dutch $(\mathrm{N}=29$, mean age 21.7, $\mathrm{SD}=6.7$ ) origin on the basis of the WHO definition of suicidal behavior, non native-Dutch last name and age. Two researchers assessed the files whether they belonged to the selection. The files were available from the archives of a public mental healthcare centre ( 95 per cent of the cases for the years 1995-2005) and an academic hospital in the city of Amsterdam (5 per cent of the cases for the years 2003-2005). Permission was granted from the Medical Ethical Committee. The case files were a collection of notes of the treatment made by psychiatric nurses, psychologists or social workers and psychiatrists (in training). Although the files were not filled out systematically, since several professionals were involved with one patient and wrote the notes, this functioned as a cross check and increased triangulation. Research indicated that immigrant females appear most at risk in the age group of 15 to 24 years old, yet our research subjects were aged between 12 to 41 years old. The rationale behind this is that suicidal behavior is known for its repetitive character (Arensman \& Kerkhof, 2003).

To clarify the extent to which social and economic class could possibly be related to overregulation, we selected Dutch control cases of which the parents had a low professional status, since it is known that non-western immigrant groups in The Netherlands often belong to the lower social-economic strata. We initially chose to investigate topics that are known in 
suicidology to be clear risk factors for suicidal behavior (Beautrais, 1998) e.g. demographics, childhood, relationship with parents, social support, relationship with partner, life events, sexual and physical abuse as well as psychiatric and psychological disorders. In addition, we also collected the occasion and method used for suicidal behavior. In a later stage, by shifting back and forth through the data on the life events of ethnic minority women, the principal researcher recognized elements of fatalistic suicide and subsequently included factors of overregulation in the analysis.

Table 1, 2 and 3 about here

The Relevance of Risk Factors of Psychiatric or Psychological Disorders and Physical or Sexual Abuse

A plausible contribution to the suicidal behavior of young immigrant women is the manifestation of psychiatric and psychological disorders. In addition, the rates of suicidal behavior are elevated amongst those having multiple diagnoses of psychiatric disorders (comorbidity). Some studies into psychiatric diagnoses among immigrants in The Netherlands hint at increased rates of certain psychiatric diagnoses e.g. an elevated prevalence of anxiety disorder and depression for Turkish immigrants aged 12 to 65, while schizophrenia appears to be more often diagnosed in Surinamese and Moroccans, whether born in the country of origin or in The Netherlands (Van Oort et al 2007, de Wit et al, 2005). However, research from the United Kingdom indicated that psychiatric disorders were significantly more common in British majority women than in South Asian immigrant women who had demonstrated suicidal behavior (Bhugra et al, 1999). These contradictory findings have prompted us to examine the psychiatric and psychological risk factors of Dutch majority young women versus the ethnic minority women who displayed suicidal behavior.

Table 4 about here 
Overall, having a psychiatric or personality disorder appears more relevant as a risk factor for Dutch (84 per cent) in comparison to Turkish (59 per cent) and Moroccan women (57 per cent) while South Asian women differ less substantially from Dutch women (67 per cent). This difference in the Dutch majority as opposed to minority women originates in seemingly higher incidences of mood and anxiety disorder in Dutch majority women. Co-morbidity is notably more often found in Dutch women (68 per cent) compared to South Asian (33 per cent), Turkish (28 per cent) and Moroccan women (27 per cent).

Research into the role of sexual and physical abuse unanimously shows that these experiences are a serious risk factor for suicidal behavior (Salander-Renberg et al, 2004, McHolm 2003). These findings motivated us to examine their contribution to our research subjects and compare the results.

\section{Table 5 about here}

In correspondence with previous research findings, the frequency of sexual abuse and physical abuse in our sample is quite high. Sexual abuse is more often mentioned in the files of Dutch young women compared to ethnic minority women, whereas physical abuse is equally reported across ethnicities. This may reflect actual disparities, but it seems plausible that a taboo around sexual abuse in cultures that value chastity and virginity, like the Turkish, Moroccan and South Asian culture (Brouwer et al, 1997) has resulted in some underreporting.

In sum, previous research findings on immigrants being more vulnerable to psychiatric disorders were not confirmed in our study and incidences of abuse were equally distributed as risk factors across ethnicities. These findings led us to suggest that psychiatric or psychological illnesses and abuse are not the key to explaining why minority women demonstrate more often suicidal behavior than majority Dutch women. Hence, we turn to explore the relevance of fatalistic suicide. 


\section{Durkheim's Fatalistic Suicide}

A theoretical prism that continues to be beneficial in suicidology today is Durkheim's standard work 'Le Suicide’ (Hamlin \&Bryn, 2006; Kushner \&Sterk, 2005). Durkheim’s goal was to account for the suicide rate by studying characteristics of individuals in their societal structure and social context. By emphasizing that suicide is a social manifestation and positing that individual motives could not explain the suicide rate, Durkheim went against previous beliefs of suicide as resulting from an entirely personal phenomenon, such as the existence of mental illness (Durkheim 1952). Durkheim's work, which resulted in a typology of suicide, must be understood as Weberian ideal types (Acevedo, 2005). 'Le Suicide' focuses on two core elements: the amount of social integration and social regulation. Social integration refers to the degree to which people in society are connected to each other, through the possession of shared beliefs, sentiments and interest in one another, and a sense of devotion to common goals. Social regulation points at the extent to which society or a social group has control over the emotions, motivations and behaviors of its individual members through the government by norms, rules and customs. According to Durkheim, the emergence of a severe lack or a very strong manifestation of either aspect could put individuals at risk for suicidal behavior (Acevedo, 2005).

Fatalistic suicide is characterized by a situation of extremely high levels of social regulations, while simultaneously social integration is low. Mutual ideas and shared feelings that should safeguard social bonding and connectedness no longer exist, yet strong regulation is present. It concerns a suicide as a result of over-regulated and thus unrewarding lives: 'futures are pitilessly blocked and passions violently choked by oppressive discipline' (Durkheim, 1952, pp. 276). Unfortunately, Durkheim himself wrote very little about fatalistic suicides, he mentioned only briefly that suicides of slaves were expected to fall into this category, as well as childless wives in the west (Durkheim, 1952). Durkheim found fatalistic suicide hardly relevant for the west. His moral position led him to emphasize the social effects of under regulation or anomic suicide following from the decline of importance of social norms due to processes of modernization. 
Despite the under reporting in Durkheim's work on fatalistic suicide, we have indicators that its features of overregulation are highly relevant to the suicidal behavior of young immigrant women in The Netherlands. For reflections of the mechanisms involved in fatalistic suicide, we turn to the arguments of scholars who have discussed it. Pearce (1989) described the subservient situation of slaves who were considered the property of their masters, as inferior and dehumanizing and as lacking control over the course of their life. Fatalistic suicide refers to environments where there is total coercion by an overwhelming force that has control over individual action (Acevedo, 2005). For the accomplishment of human desires and to arrive at satisfaction however, it is evident that individuals need to possess agency in determining their life course. When individuals experience serious oppressive forms of regulation, a consistent belief in human agency to realize social change becomes unimaginable (Acevedo, 2005). Hopelessness arises: 'the individual's existence has been completely demystified and drained of possibility. (...) Excessively controlled by social-cultural prescriptions, individual freedom and improvement of life would become non-existing' (Douglas in Pearce, 1989, pp. 122). There is too little space for individuality because collective life is too intense to allow for individual development. The individual counts for little or nothing and does not have control over one's fate, which results in a sense of powerlessness and meaninglessness.

One of the few other examples mentioned by Durkheim on fatalistic suicide is the suicide of housewives who remain without children. Even though at first the example seems rather outdated in the $21^{\text {st }}$ century, for the sake of the argument we investigate it. Durkheim argues (1952) that motherhood protects wives from suicide through its effect of social integration into family life. Durkheim thought that a childless wife could have no personal bonding with a role as merely a housewife and that she could not derive meaning from it: 'Fatalists do not derive protection from their role, for them it comes form the outside. Others that surround her reproduce the role, but not the individual who occupies it' (Bearman, 1991, pp. 520-521). This touches upon a crucial aspect. The experience of constraint begins when the regulation is not (anymore) based in accepted norms, but when these norms are not (any 
longer) internalized, judged as external and hence they can only be upheld through force. Fatalistic suicide is a reaction to a force coming from outside, perceived as unjust and that is not integrated in one's inner self. This results in feelings of individual isolation and alienation. Furthermore, an individual needs to have awareness of one's own alienation in order to perceive it as problematic (Halbwachs in Travis, 1990).

More recently, Davies and Neal (2000) investigated the suicides of young women in rural China and describe these as a clear case of fatalistic suicide, mostly because of the restricted sex roles for women. Central to these restrictions are practices of marrying off daughters by all-powerful families. These daughters subsequently live in unhappy marriages under the tyranny of the mother-in-law, who expects total compliance. Suicide rates for Chinese young women are much lower in the cities, which underscores that the risk for suicidal behavior is associated with the rural family system as well as demonstrates the pivotal role of the method commonly employed in rural China i.e. pesticide-poisoning.

In sum, the work of scholars who discussed Durkheim's fatalistic suicide defined this as involving overregulation originating from harsh moral demands, upheld through force. As a result, individuals are faced with a lack of agency and develop a sense of powerlessness and dehumanization. While norms are considered external, demanding and obtrusive and fail to be internalized by the individual, a sense of alienation is created. The individual does not experience to have meaningful relations and lacks a sense of connectedness.

\section{Overregulation in Young Immigrant Women's Lives: Intersections of Gender and}

\section{Culture}

Since it concerns females from specific ethnic minority immigrant groups in The Netherlands who display disproportionate rates of suicidal behavior in comparison to majority Dutch women, gender and ethnicity seem important factors. Having established the make up of a fatalistic suicide, the subsequent question that emerges is if there is a relation between gender and ethnicity on the one hand, and overregulation on the other. Hierarchal 
and oppressive structures of gender and ethnicity intersect in different ways for different groups. Identities cannot be reduced to a single marker because they are interlocked. Because of this entanglement, it should be investigated how the gender system and its relation with other systems of inequality and oppression may function. Multilayered and routinized forms of domination that often converge in women's lives, prompts for analysing multiple grounds of identity when considering how the social world is constructed (McCall, 2005).

Ethnic minority groups deploy cultural practices that originate in distinct sets of behavior and beliefs that often distinguish groups from a larger culture of which they are a part. As Geertz (1973) argued, cultural practices are symbolized and enacted by social actors and the context that gives such practices meaning and significance. Some cultural practices seem to have a much greater influence on the lives of (young) women than on men. In particular, in the domain of the sexual and reproductive life that is central in many cultures, women's role is often pivotal (Yuval Davis, 1997). The sphere of sexuality and reproduction is a crucial theme in cultural practices since it enables the continuity of the ethnic group. As a result, it is women in particular who are 'considered to be the guardians of the collectivity's identity and honor and who demarcate with their behavior the moral boundaries of their group' (Yuval Davis, 1997: 25). In addition, cultural traditions and sometimes the re-invention of traditions are often used as ways of legitimizing the control and oppression of women in situations in which individual men as well as the collectivity feels threatened by others.

\section{Empirical findings on Fatalistic Suicide in the Lives of Young Immigrant Women}

After analysing the accounts of young immigrant women, 8 factors of overregulation emerged that referred to fatalistic suicide. These factors were not established a priori but emerged cross-culturally as a result of the analysis of the case files when we studied the circumstances that led these young women into suicidal behavior.

Table 6 about here 
Table 6 shows that factors of overregulation emerge in about 50 per cent of the cases of Moroccan and Turkish and South Asian young women, as opposed to 24 per cent in the Dutch cases. Issues around demands of upholding chastity were found almost equally in all ethnic minority groups. (The fear of) Being outcasted appeared relevant to Turkish and Moroccan young women in particular. Incidences of forced marriages were observed mostly in Turkish young women, whereas the impossibility to opt for a divorce because of family pressure to stay in an unwanted marriage was observed in Turkish as well as Moroccan young women. Rejection of the partner by their families was found in particular in South Asian young women and Turkish young women. The threat of death could be found across ethnicity, most notably however this appears to happen to Moroccan women. Being stalked by an (ex) partner emerged as a cross-cultural problem for women. Being forced into prostitution happened to two Dutch women and one Turkish woman. In sum, 3 factors were found that affected both minority and majority women, while 5 factors around family honor were observed in ethnic minority women only. To illustrate how overregulation originating in honor related issues emerge and to illuminate the extent to which a lack of agency exists, case summaries of minority women are discussed below.

\section{Chastity Regulation: Accusations, Control and the Threat of Being Outcast}

Accounts indicate how safeguarding the family honor through maintaining a chaste (decent) reputation is felt deeply by young minority women, who face serious consequences if they fail to live up to this prescription. The case files demonstrate how the status of a chaste woman was jeopardized, and how they were subsequently faced with repercussions that appear to be associated with their suicidal behavior. As a result, some women felt they had little choice but to runaway from home: 
Her mother migrated to The Netherlands just before giving birth to her. She used to be dad's favorite, although she knows that he preferred to have a son. Later there were severe conflicts between them. She used to be very angry with him, because he would not allow her all sorts of things, like going on school trips. Her father beat her up and she tried to hit him back. Her mother was isolated and sad, because her family was in Morocco and her husband did not give her any money. Her parents' marriage was bad. Her mother cried at her shoulder instead of the other way around. When her mother was pregnant with her sister, her mother had a fight with her father and left home, but returned later. One day in her mid puberty, her father hit her on the head. She then went to stay with friends in a city. She then got introduced to drugs and criminals. At a party, she met a young man with whom she had sex for the first time. Her parents found out about this when they discovered a letter with the results of her pregnancy test. They were furious and never wanted to see her again. They pretended not to know her when they bumped into her, and thought of her as a whore. She then stayed with foster parents. At some point she contacted her family again, because she wanted to see how her younger sister was doing. Her father appeared to regret all the things that happened between them, but her mother was jealous of this and therefore talked bad about her to her father. She concludes that her parents see her as a bad child. (a Moroccan student, aged 20 who took an overdoses)

The account above shows how violent repercussions of their families follow from the loss of a woman's virginity, a cultural value of chastity, which is a woman's responsibility to bear.

\section{Marital Regulation: Rejection of the Partner and (Threats of) Being Forced into}

\section{Marriage}

Some parents and family members of young minority women who demonstrated suicidal behavior rejected their partners. In South Asian families, this often concerns a rejection on the basis of the caste, religion or ethnic background. When family members attempt to control a woman's spouse choice, they attempt to safeguard ethnic and cultural reproduction, 
and such efforts are often reinforced after migration. Rejection of the partner choice is also interlocked with agreements with family members, e.g. a match between cousins of befriended families. This is often thought to guarantee a match between upbringing, religion or class and expected to result in the continuation of steady family relations (Sterkx \& Bouw 2005). The following example illustrates the rejection by a South Asian family of the daughter's partner:

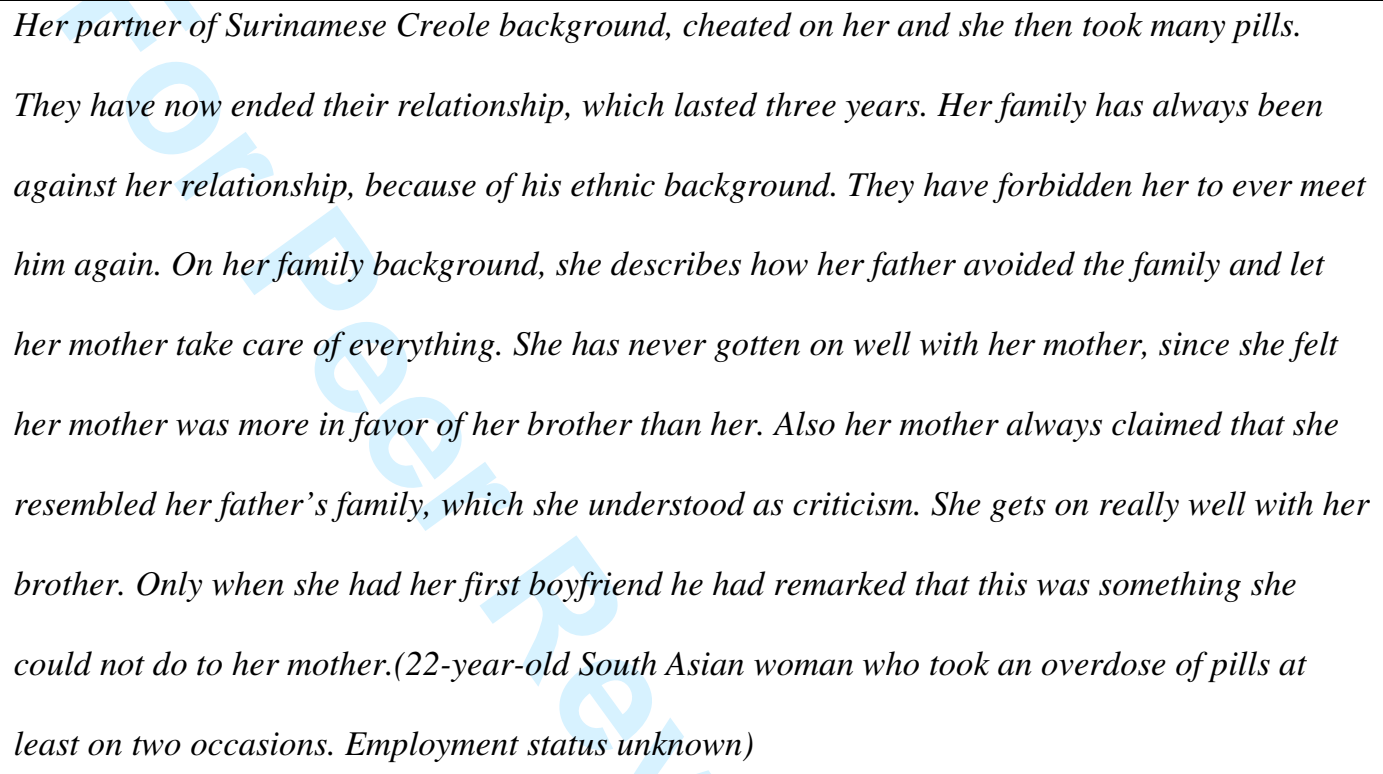

An account of a Turkish young woman also demonstrates lack of individual choice in partner selection:

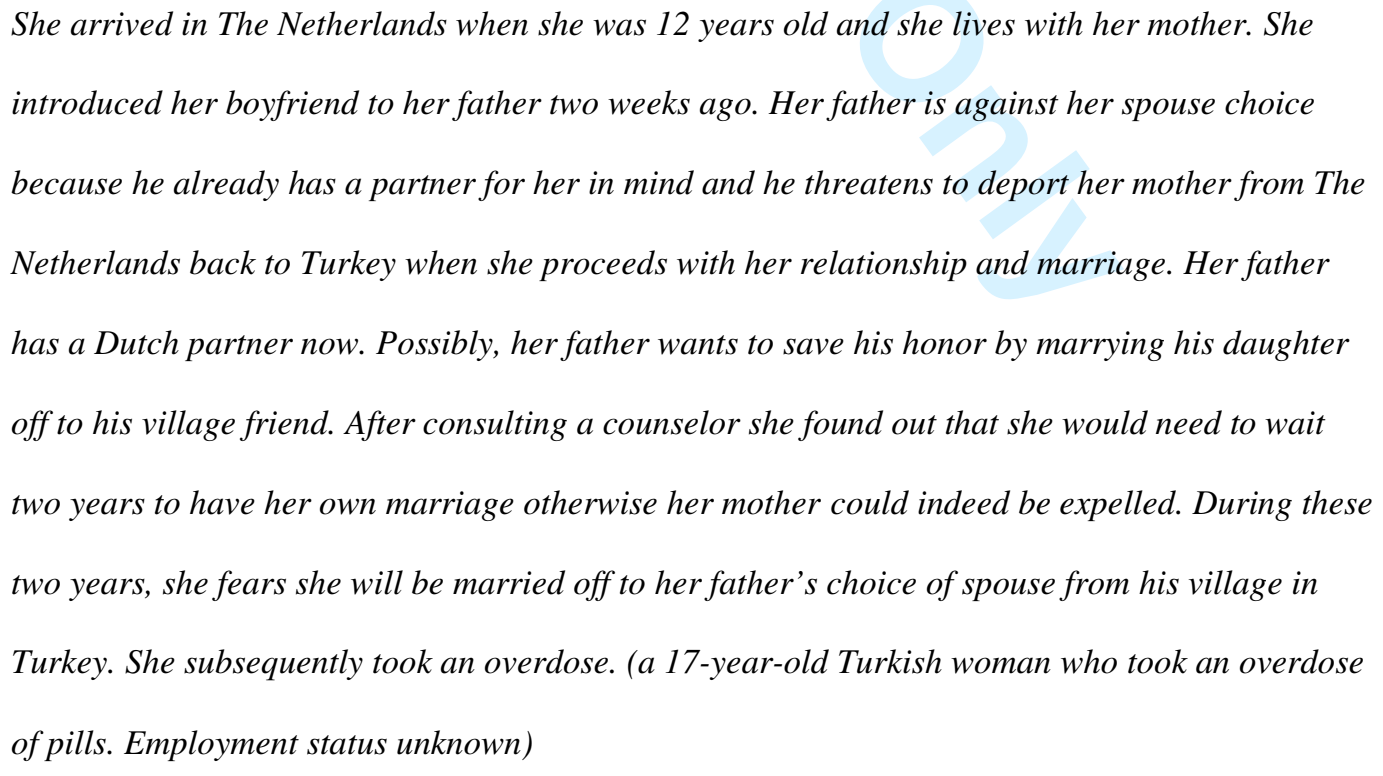


The effect of migration in the above account is the fact that the young woman's mother is dependent on her husband for her residence permit. The father who wants to force a marriage upon the daughter exploits this dependency. In the next account of a Moroccan woman, it is shown that cultural value regarding what is considered to be a respectable female, does not end when a woman is divorced:

Her family is against her relationship with a Moroccan man who has been married twice before.

Previously, her aunt supported her, but now her entire family is against the marriage. She demonstrated serious life threatening behavior. She does not want her family to find out about this; because she feels that they could blame her relationship-for her suicidal behavior. She also has serious worries about her infertility and she feels bad about the fact that her parents are divorced and her mother does not want any contact anymore. She used to be married herself but went through a divorce after 6 years of marriage, even though her husband did not agree; her family supported this, since the two of them had too different personalities. She herself is very outgoing and active, while her ex husband was more timid and preferred to stay at home. She married at a very young age with a countryman, since she felt this was the appropriate thing to do for a Moroccan woman. She is described as someone with big circle of multi- ethnic friends. (a 28 year old Moroccan woman, method unknown, employed and part-time student)

Interestingly, we observed that the woman featured above had internalized certain cultural demands around her spouse choice earlier in her life, i.e. he should be a Moroccan and that she should marry young. Later in her life, her choice for a partner clashes with her family who wants to control her partner selection in order for her to become respectable again.

\section{Force to Maintain an Unwanted Marriage by Threats of Violence or Death}

The following account indicates how family members of a Turkish woman exercise control through threatening her with isolation and how physical abuse intersects with gender and culture: 


\begin{abstract}
She reported the physical abuse she suffered from her husband at the police station. She lives with her husband at her mother's house. Three months ago, she underwent a forced marriage to her cousin, which was done in a sly way: her parents told her she needed to sign documents to report her missing passport, while in fact they were the papers for an Islamic marriage. Her family put her under great pressure to stay married and she withdrew her police report when she learnt about the consequences of her act for her family: social isolation and outcasting. Her parents threatened to kill her when she would opt for a divorce. She then took an overdose. To the psychologist, her suicidal behavior seems to be a way out of her powerless position. (20-year-old Turkish woman who took an overdose of pills, employment status unknown)
\end{abstract}

In the following account of a Moroccan woman, it can be highlighted how cultural negative attitudes towards divorced women precipitate a conflict between loyalty towards the family and a woman's personal wishes as an individual:

She grew up in Morocco with many siblings and was her father's favorite. Her father was sweet and kind, while her mother was very strict and punished her very often. She hardly has a support system; all her family members live in Morocco. She married her first husband when she was 21 years old. She wanted to continue her education, but had to get married and then moved to The Netherlands to be with her husband. Her husband had a job in education, yet he did not want her to continue her studies in The Netherlands. Her husband already had a few children from his previous marriage. He puts pressure on her to take birth control pills and to have an abortion when she gets pregnant. Her relationship with her husband has not turned out as she had hoped for. Since she has given birth to a child, her husband has changed substantially. He became a very religious man and this clashes with her views. She struggles what to do now, if she wants to stay in her marriage, she would have to give up her own perspective of raising the children. If she would follow her heart, she would lose her family and family honor. (Moroccan woman, aged 34 who took an overdosed on several occasions, employed in education) 


\section{Conclusion and Discussion}

Our data shows that well known risk factors in suicidology that consist of psychiatric and psychological illness as well as sexual and physical abuse do not appear to be sufficient to clarify the rationale of the suicidal behavior of young women of Turkish, Moroccan and South Asian origin. We observed that many minority women reported living conditions characterized by overregulation, which is a central feature of fatalistic suicide. Our aim was subsequently to illuminate the role and mechanisms of overregulation with regard to their suicidal behavior. By studying 24 to 32 cases per ethnic group that provided details of the values and beliefs in their cultural milieu and family context, we wanted to overcome pitfalls of studying aggregated level data that often places subjects in a social and cultural vacuum.

Elements of fatalistic suicide were shown to be important in at least half of the cases of suicidal behavior among Turkish, Moroccan and South Asian young women. Honor related life events were intertwined with excessive regulation and pressure by family members to ensure a woman abided with cultural norms. This led to an absence of freedom of creating one's own life course and an underdeveloped sense of autonomy that is characteristic of fatalistic suicide. Highly demanding norms in crucial domains in life (e.g. marriage, divorce, partnership, sexuality) were experienced as oppressive. These cultural and moral practices had a huge influence on the lives of some young minority women. For instance this occurred when doubts around the reputation and virginity status of young women emerged. As a consequence of (being suspected of) violating cultural norms on appropriate female behavior, violence and sometimes (threats of having) a forced marriage took place. In addition, some minority women, had to choose between continued abuse (e.g. by the husband) on the one hand and opting for divorce and reporting to the police. The latter however subsequently rendered some women an outcast in their own community or led to a lack of residency permit. Strict control of their parents over their daughter's future spouse also emerged as central to the distress in a number of minority women. These regulatory measures originated in the efforts to ensure continuation of the family and ethnic 
community. The honor related rules prevented young women from individuation and goal fulfillment. Their suicidal behavior thus bears elements of a fatalistic suicide. It seems plausible that suicidal behavior of females in these ethnic groups can be understood as an expression of a deeper underlying need to influence their life course.

Since we matched a group of Dutch majority women with low social and economic status it seems safe to assume that the factors of overregulation are not a result of class background. Our data indicated that Dutch young women who displayed suicidal behavior did not experience as much overregulation in their lives compared to minority women. On the occasions when they did face overregulation, it concerned forced prostitution and stalking by partners rather than honor related events. It appears that overregulation that originates in honor protection is culture bound.

Durkheim asserted that the suicide rates found in various cultures were indicative of the level of social pathology (1952). This precipitates the question why some immigrant families maintain such strict enforcement of rules and moral guidelines. It appears that many immigrant communities in west are undergoing a process of cultural transition towards more individualism and greater freedom for women. Durkheim also argued that the suicide rate is a proxy for social solidarity (Bearman, 1991). Hence, the alarming rates of suicidal behavior and the fatalistic components we discovered hint at prevailing contestation in certain immigrant communities around cultural prescriptions and implying gendered traditional power relations. Tensions develop when parents employ traditional culture rationale for exercising honor related regulations in spheres where young women wish to employ their own wishes. This process may also be influenced by 'a general frigidity of cultures which takes place in diasporic communities' (Yuval Davis, 1997: 67), as a response to their localization in the dominant society at large that is characterized by modernization and individualization. The exercised honor regulation prevented young women from experiencing connectedness with their family and ethnic community and appears to precipitate disintegration rather than the cultural stability as desired by the family. 
The information on the lives of young women was not reported systematically and exhaustively. However, the fact that psychologists and psychiatrists wrote the notes in the files rather than sociologists renders underreporting plausible on social and cultural factors of overregulation. In addition, we focused on young women who were seen for treatment at the mental health services. It may be expected that societal regulatory factors play an even larger role among ethnic minority women who are not in touch with mental health care.

Difficulties exist in translating the background and social meaning of suicidal behavior across different cultures. Anthropological studies into attitudes on suicidal behavior could help to illuminate if suicidal acts are recognized in an ethnic community as a response to certain kind(s) of distress. South Asian women are known to be vulnerable to suicidal behavior world wide, which may indicate a lower threshold and cultural rationale for suicidal behavior since it is engrained in their cultural repertoire (Patel \& Gaw, 1996; Raleigh et al 1990). By contrast, since the Islam fiercely forbids suicide, the threshold for suicidal behavior seems higher in Moroccan and Turkish women.

On the basis of our data, we have shown that overregulation is central to the accounts of many young suicidal minority women in the Netherlands. Analogous to the work of Kushner and Sterk, who asserted that (2005, pp. 1141): 'Durkheim's definition of fatalism described the psychological and social condition of many women (...) who inhabit the globe today', we would like to emphasize how fatalistic suicide needs to be re-evaluated as a concept in suicidology. The reason why there has been a lack of attention to fatalistic suicide may be that although women attempt suicide more often than men, since the suicidal behavior of males is more often lethal, it is frequently taken as a yardstick for research on suicidal behavior (Canetto \& Lester 1995). In conclusion, factors of overregulation should be borne in mind for future directions in suicidology as well as for developing strategies for suicide prevention for Turkish, South Asian and Moroccan young immigrant women in The Netherlands. 


\title{
Notes
}

\begin{abstract}
${ }^{1}$ Turkish and Moroccan immigrants arrived as guest labourers in the 1970's and the majority stayed in The Netherlands. The South Asian migration history goes back to late 19th century when contract labourers were shipped from India to the previous Dutch colony of Surinam to work in agriculture. Shortly before Surinam gained its independence in the 1970's, many Surinamese moved to The Netherlands. The South Asians-Surinamese mostly settled in The Hague. It is therefore expected that the ethnic group among the Surinamese that is at risk for suicidal behavior is mostly South Asian. Approximately $85 \%$ of the South Asian- Surinamese population is Hindu and 15\% is Muslim.
\end{abstract}

${ }^{2}$ Incidences of suicidal behavior as registered by hospitals and emergency agencies in the city of The Hague in 2002-2003: Turkish young females aged 15-19: 5.0 incidences per 1000 per year. Turkish young women: 20-24 year old 7.0 per 1000 per year. Surinamese young women aged 15-19 year old 4.5 per 1000 and aged 20-24 year-old, 4.0 per 1000 per year. Moroccan young women aged 15-19 year-old 2.3 per 1000 per year and aged 20-24 year old, 2.0 per 1000 per year. Dutch majority women aged 15-19 year old 1.0 per 1000 per year and 20-24 years old: 1.5 per 1000 per year.

\footnotetext{
${ }^{3}$ Statistics show that men commit 2-3 times more suicide than women in The Netherlands. South Asian men have increased rates compared to Dutch men, while rates of Moroccan and Turkish men were about $80 \%$ of that of Dutch men (100\%). South Asian and Turkish men commit suicide 3 times as often as women in these groups. Moroccan and Dutch men commit suicide about twice as often as women in their ethic groups (Garssen et al, 2006)

${ }^{4}$ Two women, from India and Bangladesh were added to the sample of South Asians because of commonalities in their region of origin.
} 


\section{References}

ACEVEDO, GABRIEL A. (2005) Turning Anomie on its Head. Fatalism as Durkheim's Concealed and Multidimensional Alienation Theory. Sociological Theory vol. 23, no. 1 pp. $75-85$

ARENSMAN, ELLA and KERKHOF, AD J.F.M. (2003) Repetition of Attempted Suicide: Frequent, but Hard to Predict. in Diego de Leo, Unni Bille Brahe, A.J.F.M. Kerkhof and Armin Schmidtke (eds) Suicidal Behavior. Theories and Research Findings, Gottingen,: Hogrefe \& Hubers Publishers

BEARMAN, PETER S. (1991) The Social Structure of Suicide. Sociological Forum vol. 6, no. 3 pp. $501-24$

BEAUTRAIS, ANNETTE L. (1998) Risk Factors for Suicide and Attempted Suicide among Young People. In: Commonwealth Department of Health and Aged Care, National Youth Suicide Prevention Strategy - Setting the evidence-based research agenda for Australia (A literature review), Canberra, Australia

BEAUTRAIS, ANNETTE L. (2003) Suicide and Serious Suicide Attempts in Youth: a Multi-Group Comparison Study. American Journal of Psychiatry vol. 160: 10931099

BHUGRA, DINESH, DESAI, MANISHA, BALDWIN DAVID S. BALDWIN and JACOB KS (1999) Attempted Suicide in West London 2. Intergroup Comparisons. In Psychological Medicine vol. 29 pp. 1131 
BROUWER, LENIE, LALMAHOMED, BEA and JOSIAS, HENNA (1992) het Weglopen van Turkse, Marokkaanse, Hindostaanse en Creoolse meisjes. Utrecht: Van Arkel

BURGER, IRENE, HEEMERT BERT VAN, BINDRABAN CLAUDIA A. and SCHUDEL JOOST (2005) Parasuicides in Den Haag: Meldingen in de Jaren 2000-2004. Epidemiologisch Bulletin, Vol. 40, no. 4 pp. 2-8

CANETTO, SILVIA SARA and LESTER, DAVID (1995) Epidemiology of Women's Suicidal Behavior. CANETTO SILVIA SARA and LESTER, DAVID (eds) Women and Suicidal Behavior. New York, Springer 1995, pp. 35-57

DAVIES CHRISTIE and NEAL, MARK (2000) Durkheimian Altruistic and Fatalistic Suicide. in Pickering W.F.S and Walford Geoffrey (eds) Durkheim's Suicide, a Century of Research and Debate pp. 36-53

DE LEO, DIEGO, BURGIS, SHELLY, BERTOLOTE, JOSE M, BILLE BRAHE, UNNI and KERKHOF Ad J.F.M. (2006) Definitions of Suicidal Behavior. Crisis, the Journal of Crisis Intervention and Suicide Prevention, vol. 27, no.1 pp. 4-15

DE WIT, MATTY (2005) Psychische Stoornissen bij Migranten, Amsterdam: GGD

DURKHEIM, EMILE (1952) Suicide. New York: The Free Press

HAMLIN, CYNTIA L. and BRYN ROBERT J. (2006) The Return of the Native: A Cultural and Social-Psychological Critique of Durkheim's Suicide Based on the GuaraniKaiowa of Southwestern Brazil. Sociological Theory, vol. 24, no. 1, pp. $42-57$ 
HJELMELANDT, HEIDI, KNIZEK, BIRTHE and NORDVIK HILMAR (2002) The Communicative Aspect of Nonfatal suicidal behavior--are there Gender Differences? Crisis, the Journal of Crisis Intervention and Suicide Prevention, vol. 23 no 4 pp. $144-55$

GARSSEN, JOOP M. HOOGEBOEZEM, JAN and.KERKHOF AD J.F.M (2006)

Zelfdoding onder Migrantengroepen en Autochtonen in Nederland. Nederlands Tijdschrift voor Geneeskunde vol. 150 no. 39 pp.2143-2149

GEERTZ, CLIFFORD (1973) The Interpretation of Culture. Selected Essays. New York, Basic Books

IGA, MIMORU (1981) Suicide of Japanese Youth. Suicide and Life Threatening Behavior, vol.11, no.1 pp.17-30

KRIKKE, HANS, NIJHUIS, HANS and WEESENBEEK, RIANNE (2000) Aan de Grenzen. Suïcidaal Gedrag onder Allochtone Meisjes en Jonge Vrouwen. Den Haag, Bureau Public Health Service.

KUSHNER, HOWARD and STERK, CATHERINE (2005) The Limits of Social Capital: Durkheim, Suicide and Social Cohesion, American Journal of Public Health, vol. 95, no. 7 pp. $1139-43$

MC CALL, LESLEY (2005) the Complexity of Intersectionality. Signs, Journal of Women in Culture and Society vol. 30, no. 3 pp. 1771-1800

MCHOLM, ANGELA E. MACMILLAN, HARRIET L, JAMIESON, ELLEN (2003) The 
Relationship Between Childhood Physical Abuse and Suicidality Among Depressed Women: Results From a Community Sample. American Journal of Psychiatry vol. 160 no. 5 pp. $933-938$

PATEL, S.P. and GAW, A. (1996) Suicide among Immigrants From the Indian Subcontinent: A Review. Psychiatric Services. Vol.47 no.5 pp.517-521

RALEIGH, VS., BULUSU, L., and R. BALARAJAN (1990) Suicides among Immigrants from the Indian Subcontinent. British Journal of Psychiatry. 156 pp. 46-50

PEARCE, FRANK (1989) The Radical Durkheim, London: Unwin Hyman Ltd

SALANDER-RENBERG, ELEONOR, LINDREN, SYBILLA and OSTERBERG, INGER (2004) Sexual Abuse and Suicidal Behaviour. In Diego de Leo, Unni Bille Brahe, A.J.F.M. Kerkhof and Armin Schmidtke (eds) Suicidal Behavior. Theories and Research Findings, Gottingen,: Hogrefe \& Hubers Publishers

SALVERDA, ELIZABETH (2004) Laat me los hou me vast. Een kwalitatieve studie naar het welbevinden van Hindostaanse meisjes in Den Haag, Den Haag, GGD rapport

STERKX, CAROLIEN and BOUW, LEEN (2005) Liefde op Maat. De Partnerkeuze van Turkse en Marokkaanse jongeren, Amsterdam: het Spinhuis

TRAVIS, ROBERT (1990) Suicide in Cross Cultural Perspective. International Journal of Comparative Sociology vol. 16, no. 3-4 pp: 237-248

VAN BERGEN, DIANA D., SMIT, JOHANNNES H, KERKHOF, A.J.F.M and SAHARSO, SAWITRI (2006) Gender and Cultural Patterns of Suicidal Behavior. 
Hindustani young Women in The Netherlands. Crisis, the Journal of Crisis Intervention and Suicide Prevention, vol. 27, no. 4 pp.181-188

\section{VAN OORT, FLOOR A., JOUNG, I.M.A, VAN DER ENDE, JAN, MACKENBACH}

JOHAN P, VERHULST FRANK C and CRIJNEN ANTON.A.M. (2007)

Development of Ethnic Disparities in Internalizing and Externalizing Problems from Adolescence into Young Adulthood. Ethnicity and Health, vol. 48, no. 2 pp. 176-84 
DIANA VAN BERGEN is a PhD candidate in the department of Sociology at VU University.

ADRESS: Department of Sociology, VU University Amsterdam, De Boelelaan 1081, 1081 HV, Amsterdam, The Netherlands. Email: D.van.Bergen@fsw.vu.nl

JOHANNES H. SMIT is a Professor in survey methodology in the department of Sociology at VU University Amsterdam and in the Department of Psychiatry at VU Medical Center in Amsterdam.

ADRESS: Department of Psychiatry at VU Medical Center, A.J. Ernststraat 887, 1081 HL, Amsterdam, The Netherlands. Email: jansm@ggzba.nl

ANTON J.L.M. VAN BALKOM is a professor in the department of psychiatry of VU University and works as a clinician at VU Medical Center in Amsterdam. ADDRESS: Department of Psychiatry at VU Medical Center, A.J. Ernststraat 887, 1081 HL, Amsterdam, The Netherlands. Email: tonb@ggzba.nl

SAWITRI SAHARSO is a professor in intercultural management at the school of management and governance at the University of Twente and in the department of Sociology at VU University, The Netherlands.

ADDRESS: School of management and governance at the University of Twente, Postbus 217, 7500 AE, Enschede The Netherlands. Email: s.saharso@utwente.nl 
Table 1: the marital status of female outpatients of four ethic groups in Amsterdam

\begin{tabular}{lcccc}
\hline & Turkish & Moroccan & South Asian & Dutch \\
& $\mathrm{N}=32$ & $\mathrm{~N}=30$ & $\mathrm{~N}=24$ & $\mathrm{~N}=29$ \\
& $\mathrm{~N}(\%)$ & $\mathrm{N}(\%)$ & $\mathrm{N}(\%)$ & $\mathrm{N}(\%)$ \\
\hline Single & & & & \\
With a Partner & $6(19)$ & $7(23)$ & $9(38)$ & $12(41)$ \\
Married & $9(28)$ & $9(30)$ & $6(25)$ & $10(34)$ \\
Divorced & $11(34)$ & $6(20)$ & $3(13)$ & $2(7)$ \\
Separating & $4(13)$ & $6(20)$ & $6(25)$ & $5(17)$ \\
& $2(6)$ & $2(7)$ & $0(0)$ & $0(0)$ \\
\end{tabular}


Table 2: Method used in suicidal behavior of female outpatients of four ethic groups in Amsterdam

\begin{tabular}{lcccc}
\hline & Turkish & Moroccan & South Asian & Dutch \\
& $\mathrm{N}=32$ & $\mathrm{~N}=30$ & $\mathrm{~N}=24$ & $\mathrm{~N}=29$ \\
& $\mathrm{~N}(\%)$ & $\mathrm{N}(\%)$ & $\mathrm{N}(\%)$ & $\mathrm{N}(\%)$ \\
\hline & & & & \\
Auto intoxication with medication and or alcohol & $24(75)$ & $22(73)$ & $15(63)$ & $20(69)$ \\
Self cutting & $7(22)$ & $4(13)$ & $6(25)$ & $9(31)$ \\
Self poisoning with acid & $0(0)$ & $0(0)$ & $4(17)$ & $1(3)$ \\
Other method & $3(9)$ & $7(23)$ & $7(29)$ & $5(17)$ \\
Multiple methods & $3(9)$ & $5(17)$ & $8(33)$ & $6(21)$ \\
& & & & \\
\hline
\end{tabular}


Table 3: Extent of repetitive suicidal behavior and lethal intent of suicidal behavior of female outpatients of four ethic groups in Amsterdam

\begin{tabular}{lrrrr}
\hline & Turkish & Moroccan & South Asian & Dutch \\
& $\mathrm{N}=32$ & $\mathrm{~N}=30$ & $\mathrm{~N}=24$ & $\mathrm{~N}=29$ \\
& $\mathrm{~N}(\%)$ & $\mathrm{N}(\%)$ & $\mathrm{N}(\%)$ & $\mathrm{N}(\%)$ \\
\hline Repetitive suicidal behavior & $18(56)$ & $14(47)$ & $16(67)$ & $16(55)$ \\
Lethal intent & $8(25)$ & $5(17)$ & $6(25)$ & $4(14)$ \\
& & & & \\
\hline
\end{tabular}


Table 4: Risk factors of psychiatric \& personality disorders of female outpatients who displayed suicidal behavior, in 4 ethic groups

\begin{tabular}{lcccc}
\hline & Turkish & Moroccan & South Asian & Dutch \\
& $\mathrm{N}=32$ & $\mathrm{~N}=30$ & $\mathrm{~N}=24$ & $\mathrm{~N}=29$ \\
& $\mathrm{~N}(\%)$ & $\mathrm{N}(\%)$ & $\mathrm{N}(\%)$ & $\mathrm{N}(\%)$ \\
\hline Mood Disorders & $12(38)$ & $11(37)$ & $11(46)$ & $17(59)$ \\
Anxiety Disorders & $7(22)$ & $5(17)$ & $3(13)$ & $10(34)$ \\
Psychotic Disorders & $2(6)$ & $2(7)$ & $3(13)$ & $4(14)$ \\
Borderline Personality Disorder/Traits & $7(22)$ & $6(20)$ & $8(33)$ & $13(45)$ \\
Substance Abuse & $3(9)$ & $1(3)$ & $5(21)$ & $6(21)$ \\
Other Psychiatric Disorders & $4(13)$ & $7(23)$ & $5(21)$ & $5(17)$ \\
No disorder & $13(41)$ & $12(40)$ & $7(29)$ & $6(21)$ \\
One or more disorders & $19(59)$ & $18(60)$ & $17(71)$ & $23(79)$ \\
Co morbidity & $9(28)$ & $8(27)$ & $8(33)$ & $17(59)$ \\
& & & \\
* Mood disorders reported on include depression, depressive mood, dysthymia \& bipolar disorder \\
** Anxiety disorders reported on include generalized anxiety, panic disorder, phobias, social anxiety \\
disorder, obsessive-compulsive disorder \& posttraumatic stress disorder \\
*** Substance abuse include the abuse of alcohol, hard drugs or soft drugs \\
**** Co morbidity refers to having two or more disorders
\end{tabular}


Table 5: Risk factors of sexual and physical abuse in female outpatients who displayed suicidal behavior, in 4 ethic groups in Amsterdam

\begin{tabular}{lcccc}
\hline & Turkish & Moroccan & South Asian & Dutch \\
& $\mathrm{N}=32$ & $\mathrm{~N}=30$ & $\mathrm{~N}=24$ & $\mathrm{~N}=29$ \\
$\mathrm{~N}(\%)$ & $\mathrm{N}(\%)$ & $\mathrm{N}(\%)$ & $\mathrm{N}(\%)$ \\
\hline Sexual Abuse or Sexual Harassment & $6(19)$ & $5(17)$ & $5(21)$ & $11(38)$ \\
Physical Abuse & $10(31)$ & $11(37)$ & $10(42)$ & $6(21)$ \\
No Abuse & $19(59)$ & $18(60)$ & $13(54)$ & $17(59)$ \\
Either Physical or Sexual abuse & $13(41)$ & $12(40)$ & $11(46)$ & $12(41)$ \\
Both Physical and Sexual abuse & $3(9)$ & $4(13)$ & $4(17)$ & $5(17)$ \\
& & & & \\
\hline
\end{tabular}


Table 6: Factors of overregulation in female outpatients who displayed suicidal behavior, in four ethic groups in Amsterdam

\begin{tabular}{lcccc}
\hline & Turkish & Moroccan & South Asian & Dutch \\
& $\mathrm{N}=32$ & $\mathrm{~N}=30$ & $\mathrm{~N}=24$ & $\mathrm{~N}=29$ \\
& $\mathrm{~N}(\%)$ & $\mathrm{N}(\%)$ & $\mathrm{N}(\%)$ & $\mathrm{N}(\%)$ \\
\hline & & & & \\
& & & & \\
Chastity jeopardized & $3(9)$ & $4(13)$ & $0(0)$ & $0(0)$ \\
(Fear of) Outcasted by family & $2(6)$ & $3(10)$ & $0(0)$ & $0(0)$ \\
Pressure to maintain unwanted marriage & $2(6)$ & $4(13)$ & $2(8)$ & $1(3)$ \\
Threatened to death & $7(22)$ & $2(7)$ & $1(4)$ & $0(0)$ \\
(Threatened to have a) Forced marriage & $3(9)$ & $3(10)$ & $6(25)$ & $1(3)$ \\
Rejection of partner/ Being rejected as partner & $3(9)$ & $1(3)$ & $3(13)$ & $3(10)$ \\
Stalking by (ex) partner & $1(3)$ & $0(0)$ & $0(0)$ & $2(7)$ \\
Forced Prostitution & $0(0)$ & $1(3)$ & $0(0)$ & $1(3)$ \\
Forced Abortion & $0(0)$ & $1(3)$ & $0(0)$ & $0(0)$ \\
Locked up at home / Forced housekeeping & $2(6)$ & $0(0)$ & $0(0)$ & $1(3)$ \\
Restrictions on activities outside the home & $0(0)$ & $1(3)$ & $0(0)$ & $0(0)$ \\
Forced by family to give up education & $14(44)$ & $14(47)$ & $11(46)$ & $21(72)$ \\
No Factors of Regulation & $18(56)$ & $16(53)$ & $13(54)$ & $8(28)$ \\
One or more Factors of Regulation & $7(22)$ & $8(27)$ & $3(13)$ & $1(3)$ \\
Multiple Factors of Regulation & & & & \\
& & & & \\
disagrees to the marriage arrangement. This & includes those & partners & who have cooperated under \\
physical or psychic treat. & & & & \\
* In a forced marriage one or two partners does not have the agency in the marriage arrangement and \\
\end{tabular}

